\title{
Inhibition of poly(ADP-ribose) polymerase attenuates the severity of acute pancreatitis and associated lung injury
}

\author{
Ruben A Mota ${ }^{1}$, Francisco Sánchez-Bueno ${ }^{1}$, Luis Saenz ${ }^{1}$, David Hernández-Espinosa ${ }^{2}$, \\ Jaime Jimeno ${ }^{1}$, Pedro L Tornel ${ }^{3}$, Alejandro Martínez-Torrano ${ }^{4}$, Pablo Ramírez ${ }^{1}$, \\ Pascual Parrilla ${ }^{1}$ and José Yélamos ${ }^{1,5}$
}

${ }^{1}$ Department of Surgery, School of Medicine, University of Murcia, Murcia, Spain; ${ }^{2}$ Department of Medicine, School of Medicine, University of Murcia, Murcia, Spain; ${ }^{3}$ Department of Clinical Biochemistry, School of Medicine, University of Murcia, Murcia, Spain; ${ }^{4}$ Department of Pathology, School of Medicine, University of Murcia, Murcia, Spain and ${ }^{5}$ Department of Biochemistry, Molecular Biology and Immunology, School of Medicine, University of Murcia, Murcia, Spain

\begin{abstract}
The severity of acute pancreatitis results from the transmigration and activation of leukocytes within the pancreas and the local synthesis and release of proinflammatory-soluble mediators that transform a local injury into a systemic inflammatory response. Poly(ADP-ribose)polymerase-1 (PARP-1) is a nuclear DNA-binding protein that has been shown to play a relevant role in cell necrosis and organ failure in various diseases associated with inflammation. Therefore, we set out to investigate whether the genetic deletion of PARP-1 or PARP-2 (a new member of the PARP family) genes, or pharmacological inhibition of PARP activity might affect the development and severity of acute pancreatitis and pancreatitis-associated lung injury. Secretagogueinduced acute pancreatitis was achieved by 12 hourly intraperitoneal injections of cerulein in mice deficient in PARP-1 or PARP-2 genes, and wild-type (WT) littermate mice untreated or treated with PARP activity inhibitors. The severity of pancreatitis was assessed by measurements of serum amylase, lipase, interleukin-1 $\beta$ and IL-6, pancreatic water content, histologic grading and pancreas myeloperoxidase (MPO) activity. Lung injury was evaluated by quantifying MPO activity and morphological changes. We found that the severity of acute pancreatitis and pancreatitis-associated lung injury was significantly attenuated in mice lacking PARP-1, but not PARP-2, compared with WT mice. Interestingly, administration of PARP inhibitors, 3-aminobenzamide or PJ34 (N-(6-oxo-5,6-dihydro-phenanthridin-2-yl)- $N, N$-dimethyacetamide $\mathrm{HCl}$ ), in WT mice markedly decreased acute pancreatitis severity and pulmonary-associated injury in a larger extension than genetic deletion of PARP-1. Our results support the potential therapeutic application of PARP inhibitors in the development and severity of acute pancreatitis and associated lung injury.
\end{abstract}

Laboratory Investigation (2005) 85, 1250-1262. doi:10.1038/labinvest.3700326; published online 15 August 2005

Keywords: poly(ADP-ribose)polymerase; acute pancreatitis; inflammation; lung injury

Acute pancreatitis is an inflammatory disease of variable severity ranging from a mild and selflimiting to a severe form, the latter being still associated with a mortality rate of $15-25 \% .^{1,2}$ Specific and effective therapies are lacking because the pathophysiology of this disease is not yet fully understood. Acute pancreatitis involves a complex

Correspondence: Dr J Yélamos, PhD, Department of Biochemistry, Molecular Biology and Immunology, Facultad de Medicina, Campus de Espinardo, Apartado de Correos 4021, Universidad de Murcia, Murcia 30120, Spain.

E-mail: jyelamos@um.es

Received 23 April 2005; revised 24 June 2005; accepted 25 June 2005; published online 15 August 2005 cascade of local and systemic events. A still unknown triggering event converts, within the pancreas, digestive proenzymes into their active forms, leading to membrane disruption, edema, interstitial hemorrhage, necrosis, accompanied by an inflammatory response with infiltrating leukocytes that contributes to the progression of both local pancreatic destruction and systemic manifestations. Various proinflammatory cytokines, such as interleukin-1 $\beta$ (IL-1 $\beta$ ), IL-6 and tumor necrosis factor- $\alpha$ (TNF- $\alpha$ ), appear to play a major role in the inflammation associated with acute pancreatitis. ${ }^{3}$ In addition, adhesion molecules such as intercellular adhesion molecule-1 (ICAM-1) have been reported to be upregulated, promoting the migration of 
neutrophils into the pancreatic parenchyma, which has been implicated as one of the major factors that promote the worsening of pancreatitis. ${ }^{4-6}$ In same cases, the inflammatory response spreads and becomes systemic, leading most often to acute respiratory distress syndrome or, in the most severe cases, to multiple organ failure and death. ${ }^{7}$ Many of the genes encoding these inflammatory mediators are regulated by the nuclear factor $-\kappa \mathrm{B}(\mathrm{NF}-\kappa \mathrm{B})$ transcription factor. ${ }^{8}$ Accordingly, studies using a number of pancreatitis models have indicated that interventions that prevent the generation and action of proinflammatory factors such as cytokines, chemokines and adhesion molecules or the inhibition of $\mathrm{NF}-\kappa \mathrm{B}$ can reduce the severity of acute pancreatitis. $^{3,4,6,9-14}$

Recently, it has been shown that genetic or pharmacological blockade of the enzyme poly(ADPribose) polymerase-1 (PARP-1) in mice results in a defective inflammatory immune response, associated with abnormalities in the expression of NF$\kappa \mathrm{B}$-dependent genes, such as TNF- $\alpha$, and IL- $6 .{ }^{15-17}$ This defective response confers on these mice an advantage in different pathophysiological conditions associated with severe inflammation. ${ }^{15-19}$ PARP-1 is a highly conserved nuclear zinc-finger DNA-binding protein that specifically detects DNA strand breaks or nicks generated by different genotoxic agents and, using $\mathrm{NAD}^{+}$as a substrate, synthesizes and transfers ADP-ribose onto aspartic and glutamic acid residues of acceptor proteins involved in chromatin structure and DNA metabolism. ${ }^{20}$ The disruption of the PARP-1 gene allowed the discovery of a residual PARP enzymatic activity catalyzed by a novel PARP enzyme known as PARP$2 .^{21}$ PARP activity is mediated mainly by PARP-1, the best known member of the recent established PARP family, ${ }^{22}$ while PARP-2 is responsible for only $10-15 \%$ of the total PARP activity in cellular extracts fully stimulated by DNA strand breaks. ${ }^{23}$ Both PARP-1 and -2 proteins appear to possess overlapping functions, since double mutant mice are not viable. ${ }^{24}$ However, in contrast to PARP-1, the role of PARP-2 in the inflammatory response is unknown.

In the current study, we have used a wellcharacterized secretagogue-induced murine model of acute pancreatitis to ascertain the role of PARP-1 and -2 in this pathological process. We found that the severity of acute pancreatitis was significantly attenuated in mice lacking PARP-1 (PARP-1 ${ }^{-1}$ ) compared with wild-type (WT) littermate mice. In addition, the severity of the associated pulmonary injury and neutrophil sequestration also decreased in PARP $-1^{-1-}$ mice compared to WT. In contrast, PARP-2-deficient mice (PARP-2 ${ }^{-1-}$ ) had pancreatitis and pulmonary-associated injury similar to those found in WT mice. Interestingly, administration of $\mathrm{N}$-(6-oxo-5,6-dihydro-phenanthridin-2-yl)- $N, N$-dimethylacetamide $\mathrm{HCl}$ (PJ34) or 3-aminobenzamide (3-AB), potent inhibitors of PARPs activity, ${ }^{25-27}$ markedly decreased pancreatitis and pulmonaryassociated injury in WT mice in a larger extension than that found in mice that had PARP-1 genetically deleted. Taken together, our results show the therapeutic potential of PARP inhibitors on the development and severity of acute pancreatitis and pancreatitis-associated lung-injury.

\section{Materials and methods}

\section{Animals}

PARP-1 ${ }^{-1-}$, PARP-2 ${ }^{-/-}$and their WT littermates mice (strain $129 / \mathrm{Sv} \times \mathrm{C} 57 \mathrm{BL} / 6$ ) were kindly provided by Dr de Murcia (Strasbourg, France). ${ }^{24,28}$ Polymerase chain reaction genotyping screening was performed as described previously. ${ }^{16,24}$ The animals were kept under standardized conditions with a 12-h light/ dark cycle. Tap water and mouse chow were provided ad libitum. The experimental procedure was performed in accordance with The University of Murcia approved institutional animal care guidelines.

\section{Induction of Experimental Pancreatitis}

PARP-1 ${ }^{-1-}$, PARP- $2^{-1-}$ and their WT littermates mice (5-7 weeks old) were given hourly intraperitoneal injections of saline (control) or saline containing a supramaximally stimulating concentration of cerulein (Sigma, St Louis, MO, USA) $(50 \mu \mathrm{g} / \mathrm{kg})$ for $12 \mathrm{~h}$. Pharmacological inhibition of PARPs was carried out by pretreatment of WT mice with PJ34 (Alexis, Carlsbad, CA, USA) $(10 \mathrm{mg} / \mathrm{kg})$ or 3 -AB (Sigma) $(30 \mathrm{mg} / \mathrm{kg})$ for $1 \mathrm{~h}$ before the first cerulein injection was administered, as described previously. ${ }^{16,29}$

\section{Sample Collection}

At the indicated times $(0,6,12$ and $24 \mathrm{~h}$ after cerulein injection), mice were killed by $\mathrm{CO}_{2^{-}}$ induced asphyxiation. Blood, pancreas and lungs were harvested for further studies. Serum samples were obtained by centrifugation of blood at $1100 \mathrm{~g}$, aliquoted and frozen at $-70^{\circ} \mathrm{C}$ until used. Organs were either immediately fixed in $4 \%$ formaldehyde (phosphate-buffered saline (PBS) diluted) and used for histology analysis, or rinsed in saline buffer, snap-frozen in liquid nitrogen and stored at $-70^{\circ} \mathrm{C}$ until used for protein extraction or immunohistochemistry.

\section{Pancreatic Edema}

The extent of pancreatic edema was evaluated by measuring the wet-to-dry weight ratio. Pancreatic tissue was weighted before and after desiccation at $85^{\circ} \mathrm{C}$ for $36 \mathrm{~h}$. The difference between the wet and dry tissue weights was calculated, and the degree of edema was expressed as a percentage of the wet tissue weight. 


\section{Myeloperoxidase (MPO) Determination}

MPO activity was measured photometrically. Tissue samples were thawed, homogenized in $1 \mathrm{ml}$ of $20 \mathrm{mM}$ phosphate buffer (pH 7.4) and then spun down at $10500 \mathrm{~g}$ for $12 \mathrm{~min}$ at $4^{\circ} \mathrm{C}$. The resulting pellet was resuspended in $50 \mathrm{mM}$ phosphate buffer (pH 6.0) containing $0.5 \%$ hexadecyltrimethyl ammonium bromide (Sigma). Homogenates were then frozen in liquid nitrogen and thawed on four consecutive occasions before a final $40 \mathrm{~s}$ sonication. Samples were spun down at $10500 \mathrm{~g}$ for $12 \mathrm{~min}$ at $4^{\circ} \mathrm{C}$ and supernatants were collected for MPO assay. The assay mixture consisted of $10 \mu \mathrm{l}$ supernatant, $25 \mu \mathrm{l} 33^{\prime} 55^{\prime}$-tetramethylbenzidine (Sigma) (final concentration, $1.6 \mathrm{mM}$ ), $25 \mu \mathrm{l} \mathrm{H}_{2} \mathrm{O}_{2}$ (Sigma) (final concentration, $0.3 \mathrm{mM}$ ) diluted in $80 \mathrm{mM}$ phosphate buffer (pH 5.4) and $40 \mu \mathrm{l}$ of $50 \mathrm{mM}$ phosphate buffer (pH 6.0) containing $0.5 \%$ hexadecyltrimethyl ammonium bromide. This mixture was incubated at $37^{\circ} \mathrm{C}$ for $2 \mathrm{~min}$. The reaction was stopped with $\mathrm{HCl}$ $1 \mathrm{~N}$ and absorbance was measured at $450 \mathrm{~nm}$. An enzyme unit is defined as the amount of enzyme that produces an increase of 1 absorbance unit/min.

\section{Histological and Immunohistochemical Analysis}

For histopathological analysis, formaldehyde-fixed specimens were embedded in paraffin, cut in sections of $4 \mu \mathrm{m}$ and stained with hematoxylin and eosin (H\&E). Analysis of the histopathological changes in pancreas and lung was carried out under light microscopy by two expert pathologists who were blind to the experiment. Pancreatic histological grading of edema, necrosis and infiltration of inflammatory cells was scored by assigning a subjective value as described previously: ${ }^{30} 0$, absent; 1, mild; 2, moderate; and 3, severe. Grading of vacuolization was based on the approximate fraction of cells involved: 0 , absent; $1,0-5 \% ; 2,5-20 \%$; and $3,>20 \%$.

Immunohistochemical staining was performed using the DAKO Autostaining Universal staining system (DAKO, Glostrup, Denmark). For detection of poly(ADP-ribose) (PAR), tissue sections were deparaffinized, rehydrated and treated with peroxidaseblocking reactive (DAKO) for $5 \mathrm{~min}$. Trichloroacetic acid $(10 \%)$ was then applied to sections for $15 \mathrm{~min}$ to prevent catabolism of the polymer by poly(ADPribose) glycohydrolase. The slides were then incubated with rabbit anti-PAR polyclonal antibody (Biomol, Plymouth Meeting, PA, USA) for $2 \mathrm{~h}$ at room temperature. Then, sections were washed three times with PBS with $0.1 \%$ Tween-20 (TBS) and incubated with anti-rabbit horseradish peroxidase-labeled secondary antibody (Amersham Biosciences, Bucks, UK). For macrophages detection, pancreas cryostat sections of $4 \mu \mathrm{m}$ were prepared and fixed in acetone for $30 \mathrm{~min}$. Then, sections were incubated with rat anti-mouse F4/80 mAb (Caltag,
Burlingame, CA, USA) overnight, washed three times in TBS and incubated with goat anti-rat horseradish peroxidase-labeled secondary antibody (Sigma). After extensive washing, diaminobenzidine chromogen (DAKO) for 5 min was used to develop the sections. Finally, after rising in distilled water, the slides were counterstained with hematoxylin, rinsed well with tap water and mounted.

\section{Amylase, Lipase and Cytokine Determination}

Serum concentration of lipase and amylase was measured using commercial kits according to the manufacturer's protocols in a Modular P800 photometric analyzer (Roche, Mannheim, Germany). The serum level of IL- 6 and IL- $1 \beta$ was determined by ELISA, according to the manufacturer's protocols (Bender MedSystems, San Bruno, CA, USA for IL-6, and R\&D Systems, Abingdon, UK for IL-1 $\beta$ ). Tissue levels of pancreatic IL-6 were measured by ELISA after homogenizing a sample of freshly obtained tissue and cytoplasmic protein extraction using a nuclear extract kit (Active Motif, Carlsbad, CA, USA) according to the manufacturer's protocols.

\section{Statistical Analysis}

Results are presented as mean values \pm standard error of mean (s.e.m.). Statistical analysis was performed by using the Mann-Whitney nonparametric $t$-test. A $P$-value $<0.05$ was considered statistically significant.

\section{Results}

\section{Effect of Genetic and Pharmacological Blockade of PARP on the Severity of Cerulein-Induced Acute Pancreatitis}

To examine the contribution of PARPs on the development and severity of acute pancreatitis, mice deficient for PARP-1 or PARP-2, and WT mice untreated (WT) or treated with PJ34 (WT $\left.{ }^{\mathrm{PJ3} 3}\right)$, or 3$\mathrm{AB}\left(\mathrm{WT}^{3-\mathrm{AB}}\right)$ PARPs inhibitors were challenged with 12 hourly intraperitoneal injections of the secretagogue cerulein at a supramaximal dose. This treatment has been previously shown to induce acute necrotizing pancreatitis in mice. ${ }^{31}$ The severity of cerulein-induced pancreatitis was evaluated by measuring the levels of amylase and lipase in serum, and pancreatic water content, and morphological evidence of the extent of acinar cell injury/necrosis by standard histological examination. As shown in Figure 1, treatment of WT mice with cerulein markedly increased the levels of amylase and lipase in serum, and pancreatic water content at $12 \mathrm{~h}$ from the start of cerulein administration. At this time point, both PARP-1 $1^{-1-}$ and PARP-2 ${ }^{-1-}$ mice displayed a significant reduction in serum amylase levels (Figure 1a), and reduction, which did not 

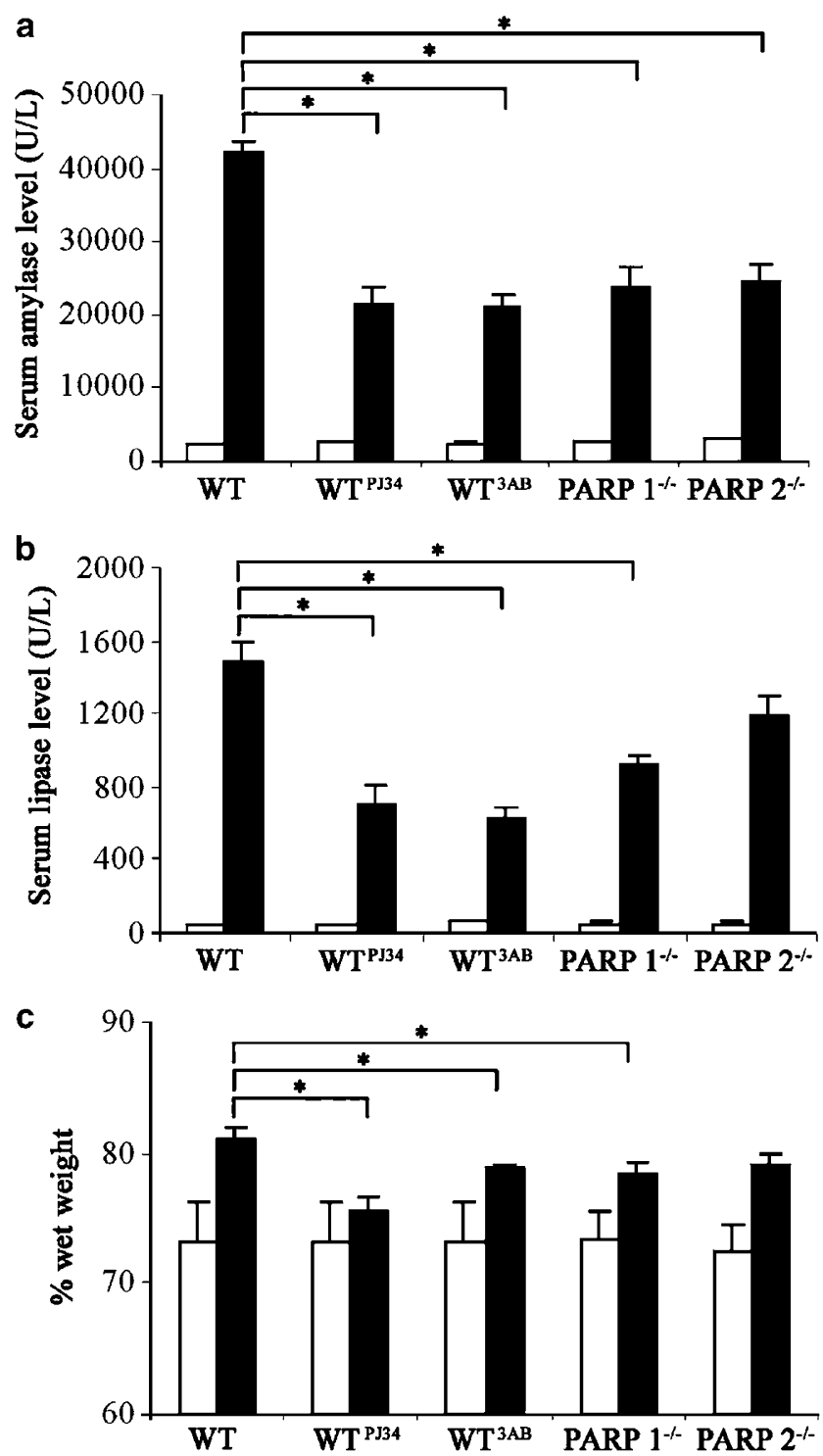

Figure 1 Effects of genetic and pharmacological inhibition of PARP on cerulein-induced pancreatic injury. WT, WT PJ34treated $\left(\mathrm{WT}^{\mathrm{PJ} 34}\right)$, WT 3-AB-treated $\left(\mathrm{WT}^{3-\mathrm{AB}}\right), \mathrm{PARP}^{-1-} 1^{-1}$ and PARP-2 ${ }^{-1-}$ mice were administered 12 hourly injections of $50 \mu \mathrm{g} / \mathrm{kg}$ cerulein (black bars). The same numbers of control animals from each experimental group received saline (white bars). (a) Serum amylase levels, (b) serum lipase levels and (c) pancreatic water content were measured as described in the Materials and methods section. Results are expressed as mean \pm s.e.m. ${ }^{*} P<0.05$ was considered significant. This figure shows data for 10 to 18 mice per group.

reach statistically significance in PARP- $2^{-/-}$mice, in serum lipase levels and pancreatic water content compared to the same parameters in their WT littermates (Figure $1 \mathrm{~b}$ and $\mathrm{c}$ ). Interestingly, $\mathrm{WT}^{\mathrm{PJ} 34}$ and $\mathrm{WT}^{3-\mathrm{AB}}$ mice showed the greatest reduction in the serum levels of amylase and lipase as well as a statistically significant reduction in pancreatic water content compared to those of WT mice after cerulein-induced pancreatitis, suggesting a cumulative protective effect after inhibiting PARPs activity.
Morphological analysis of H\&E-stained pancreas sections from WT mice after the cerulein challenge revealed large infiltrates mainly composed of polymorphonuclear and some mononuclear cells, interstitial edema that even disrupted the architecture of the acini and features of vacuolization and necrosis of the acinar cells, representative traits of acute pancreatitis (Figure 2). Similar morphological findings were found in cerulein-treated PARP-2 ${ }^{-1-}$ mice (Figure 2). In contrast, PARP-1 ${ }^{-1-}, \mathrm{WT}^{\mathrm{PJ} 34}$ and $\mathrm{WT}^{3-\mathrm{AB}}$ mice, at the same time point, displayed attenuated morphological changes associated with acute pancreatitis (Figure 2). Neither of the experimental groups treated with saline exhibited any morphological evidence of acute pancreatitis (Figure 2). To assess these morphological changes in a semiquantitative manner, slides were scored by two pathologists in a blinded manner. In all histologic parameters, there was a slight decrease in severity in the PARP- $1^{-1-}$ mice receiving cerulein compared to WT cerulein-treated mice, with a decrease in total histologic score from $7.932 \pm 0.632$ in WT to $4.982 \pm 1.149$ in PARP- $1^{-1-}$ mice $(P<0.05)$ (Figure 3). More importantly, treatment of WT mice with either PJ34 or 3-AB PARP inhibitors strongly reduced the severity of the cerulein-induced pancreatitis, as noted by a statistically significant decrease in pancreatic edema, inflammation, vacuolization and necrosis, with a decrease in total histologic score from $7.932 \pm 0.632$ to $2.875 \pm 0.471(P<0.05)$ in $\mathrm{WT}^{\mathrm{P} J 34}$ mice and to $3.438 \pm 0.145(P<0.05)$ in $\mathrm{WT}^{3-\mathrm{AB}}$ mice (Figure $3)$. In contrast, PARP-2 deficiency had no significant protective effect on these histologic parameters (Figure 3). Immunohistochemical analysis for PAR in pancreas sections obtained from WT and PARP- $2^{-1-}$ mice, harvested after 12 hourly intraperitoneal injections of cerulein revealed a positive staining in injured pancreas (Figure 4). In contrast, no staining for PAR was found in the pancreas of PARP-1 $1^{-1-}$ or WT mice treated with PARP inhibitors (PJ34 or 3-AB) after 12 hourly injections of cerulein (Figure 4). Neither of the experimental groups treated with saline exhibited PAR staining.

\section{PARP-1 Inhibition Reduces Intrapancreatic MPO Activity and Macrophages Infiltration Associated with Acute Pancreatitis}

MPO activity in pancreas homogenates was determined as a measure for neutrophil accumulation within the organ (Figure 5). WT mice that received repeated cerulein injections showed a profound increase in pancreatic MPO activity. Both genetic depletion of PARP-1 and pharmacological inhibition of PARPs significantly diminished this increase in pancreatic MPO activity, the latter having the strongest inhibitory effect. Cerulein-treated PARP$2^{-/-}$mice showed a slight, not statistically significant, reduction in pancreatic MPO activity compared to cerulein-treated WT mice. 


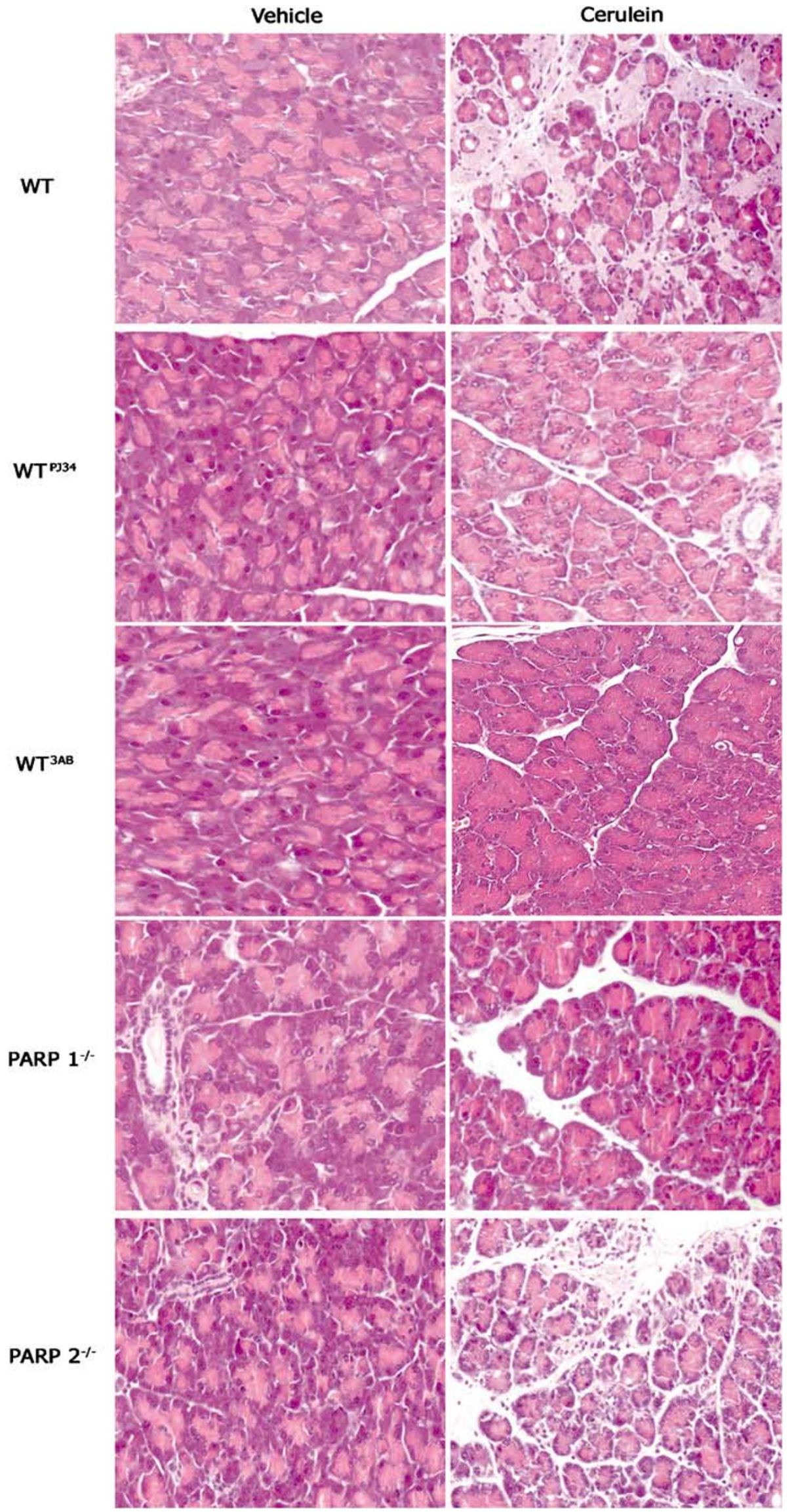


To quantify infiltrating macrophages, immunohistochemical staining using the F4/80 antibody was performed on frozen pancreas sections. As shown in Figure 6, numerous $\mathrm{F} 4 / 80^{+}$cells were found in pancreas after cerulein treatment of WT mice. In contrast, very few infiltrating $\mathrm{F} 4 / 80^{+}$ cells were found in PARP-1 ${ }^{-1-}, \mathrm{WT}^{\mathrm{PJ} 34}$ and $\mathrm{WT}^{3-\mathrm{AB}}$ cerulein-treated mice. Cerulein-treated PARP-2 ${ }^{-1-}$ mice also showed a significant reduction of infiltrating $\mathrm{F} 4 / 80^{+}$cells compared to WT cerulein-treated mice.

\section{Effect of PARPs Inhibition on Systemic Inflammatory Mediators Release after Cerulein-Induced Pancreatitis}

Several inflammatory mediators have been shown to increase in acute pancreatitis. ${ }^{7}$ Therefore, to obtain insight in the effect of PARPs inhibition in the occurrence of a systemic inflammatory response after cerulein-induced pancreatitis, serum concentrations of IL- 6 and IL- $1 \beta$ were measured. As shown in Figure 7, cerulein-induced pancreatitis in WT mice is associated with an increase in serum levels of IL- 6 and IL- $1 \beta$, reaching a peak at $12 \mathrm{~h}$. However, the increase in the levels of IL-6 in serum was significantly attenuated by the pharmacological or genetic blockade of PARP-1 $(2392 \pm 170 \mathrm{pg} / \mathrm{ml}$ in WT VS $1173 \pm 44 \mathrm{pg} / \mathrm{ml}$ in PARP-1 ${ }^{-/}, P<0.05$; and $1201 \pm 115 \mathrm{pg} / \mathrm{ml}$ in $\mathrm{WT}^{\mathrm{PJ} 34}$ mice, $P<0.05$, after 12 hourly intraperitoneal injections of cerulein). Similarly, IL-1 $\beta$ serum level was significantly reduced after pharmacological or genetic blockade of PARP-1 $(940 \pm 74 \mathrm{pg} / \mathrm{ml}$ in WT vs $552 \pm 88 \mathrm{pg} / \mathrm{ml}$ in PARP-1 $1^{-1-}, P<0.05$; and $711 \pm 97 \mathrm{pg} / \mathrm{ml}$ in $\mathrm{WT}^{\mathrm{PJ} 34}$ mice, $P<0.05$, after 12 hourly intraperitoneal injections of cerulein). In contrast, PARP-2 ${ }^{-1-}$ mice displayed similar serum levels of both IL-6 and IL$1 \beta$ to those found in WT mice treated under the same conditions (Figure 7). Serum levels of IL-6 and IL-1 $\beta$ decreased to similar levels in all animal groups $24 \mathrm{~h}$ after the initiation of the intraperitoneal injections of cerulein (Figure 7).

Figure 2 Morphological changes in cerulein-induced pancreatitis. Representative light micrographs of pancreas sections stained with H\&E from WT, WT PJ34-treated (WT ${ }^{\mathrm{PJ} 34}$ ), WT 3-AB-treated $\left(\mathrm{WT}^{3-\mathrm{AB}}\right.$ ), PARP-1 ${ }^{-1-}$ and PARP-2 ${ }^{-1-}$ mice administered 12 hourly intraperitoneal injections of $50 \mu \mathrm{g} / \mathrm{kg}$ cerulein (right column) or saline (left column). Magnifications $\times 20$.

Figure 3 Histological score of cerulein-induced acute pancreatitis. Histologic sections of pancreas from WT, WT PJ34-treated $\left(\mathrm{WT}^{\mathrm{PJ} 34}\right)$, WT $3-\mathrm{AB}$-treated $\left(\mathrm{WT}^{3-\mathrm{AB}}\right)$, $\mathrm{PARP}-1^{-1-}$ and $\mathrm{PARP}-2^{-1-}$ mice, harvested after 12 hourly intraperitoneal injections of cerulein, were scored from 0 (normal) to 3 (severe) for edema, inflammation, necrosis and vacuolization as described in the Materials and methods section. Results are expressed as mean \pm s.e.m. ${ }^{*} P<0.05$ was considered significant. This figure shows data for 10 to 18 mice per group.
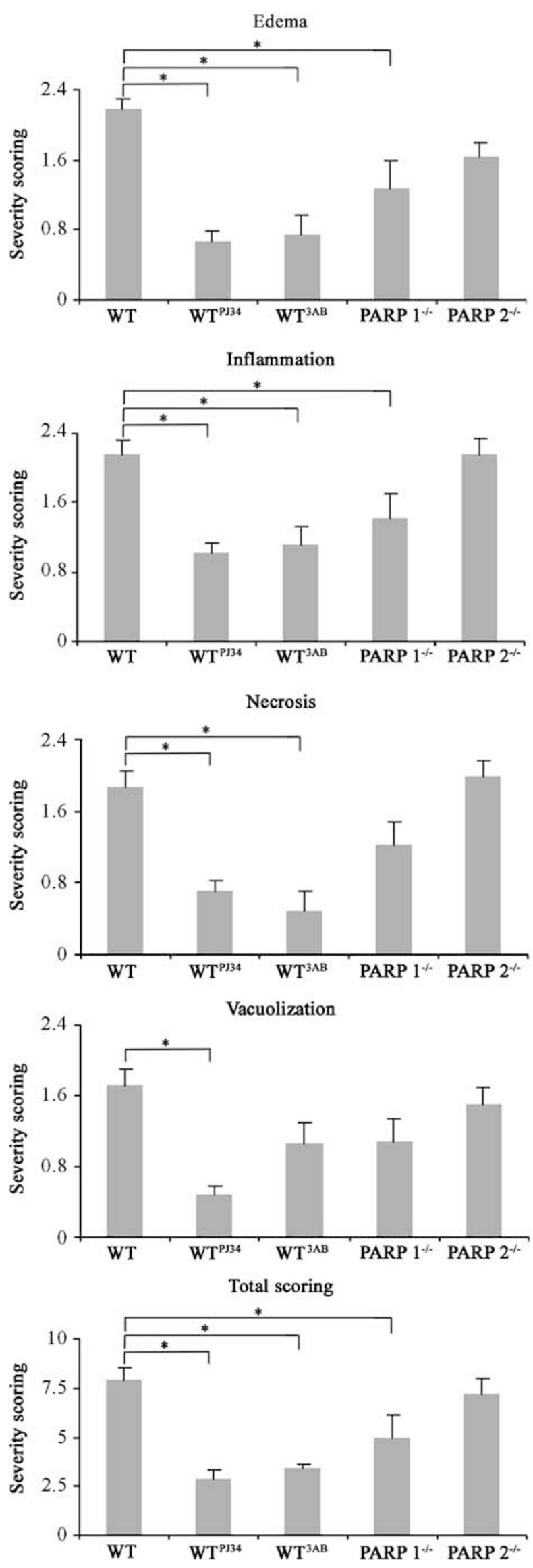

Laboratory Investigation (2005) 85, 1250-1262 

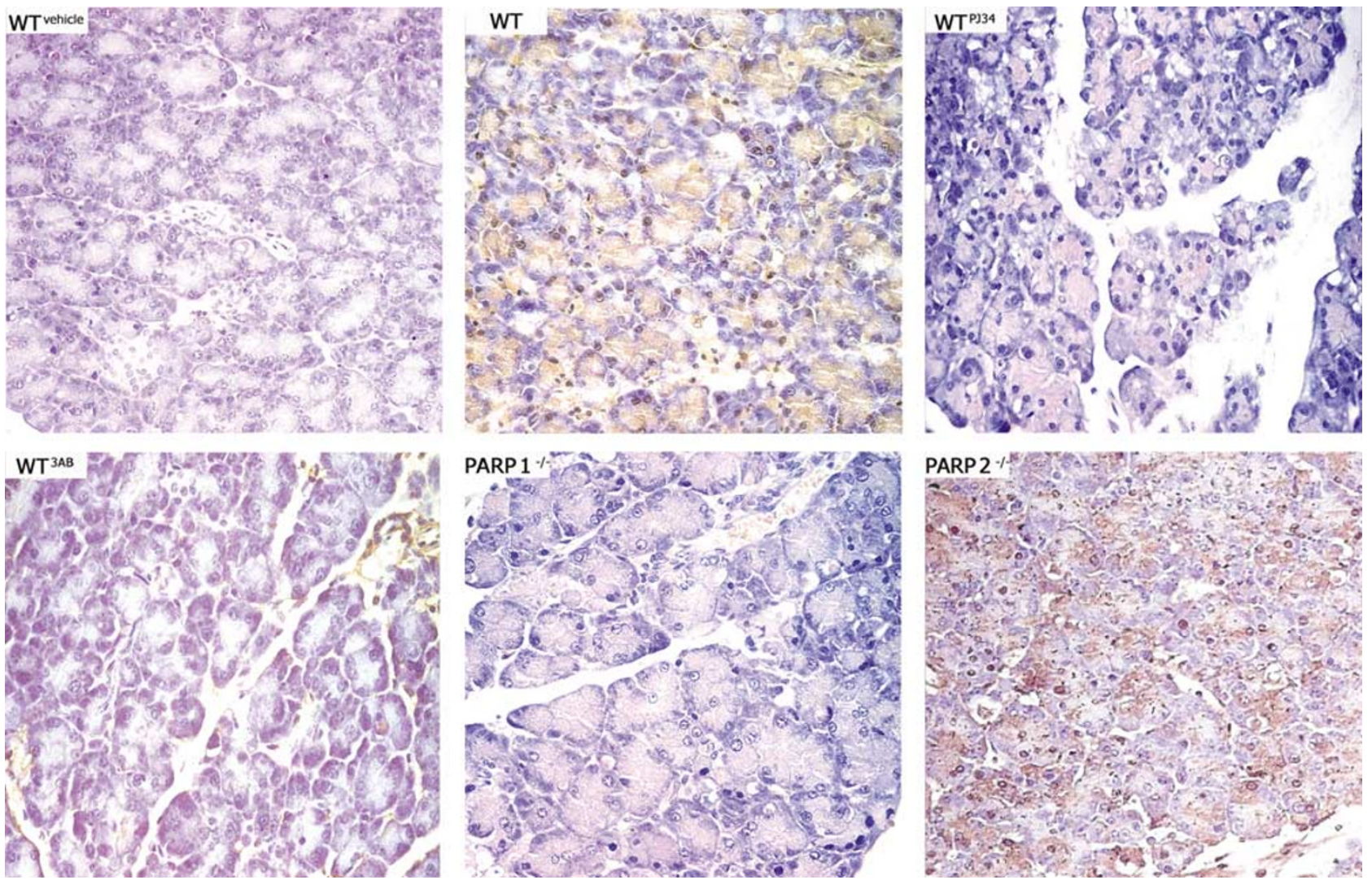

Figure 4 Immunohistochemical localization of PAR in the pancreas. Sections of pancreas from WT, WT PJ34-treated (WT ${ }^{\mathrm{PJ} 34}$ ), WT 3-ABtreated ( $\mathrm{WT}^{3-\mathrm{AB}}$ ), PARP-1 $1^{-1-}$ and PARP- $2^{-1-}$ mice, harvested after 12 hourly intraperitoneal injections of cerulein, were stained for PAR by immunohistochemistry. The pictures are representative sections from $n=4$ determinations per group.

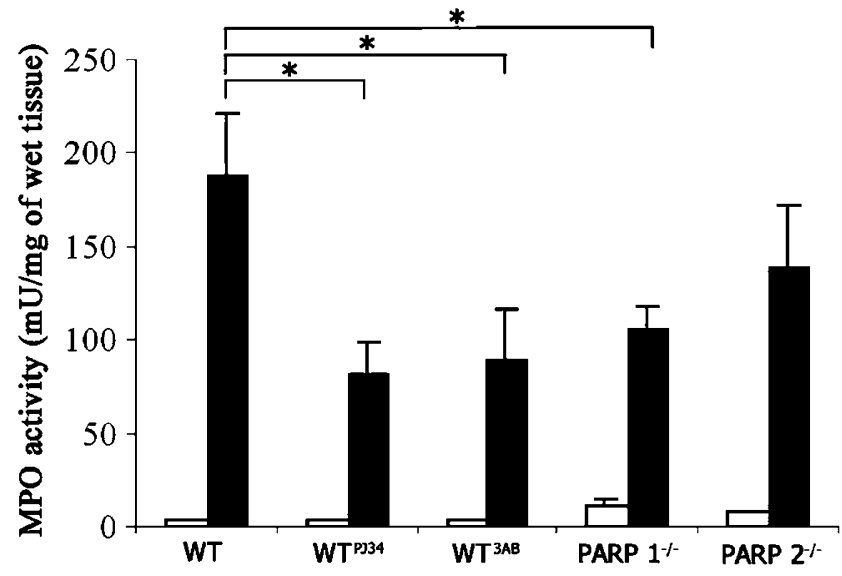

Figure 5 Effects of genetic and pharmacological inhibition of PARPs on pancreatic MPO activity. MPO activity was measured in the pancreas of WT, WT PJ34-treated (WT $\left.{ }^{\mathrm{PJ} 34}\right)$, WT 3-AB-treated $\left(\mathrm{WT}^{3-\mathrm{AB}}\right), \mathrm{PARP}-1^{-1-}$ and PARP-2 ${ }^{-1-}$ mice after 12 hourly injections of $50 \mu \mathrm{g} / \mathrm{kg}$ cerulein (black bars). Same numbers of control animals from each experimental group received saline (white bars). Data are expressed as MPO activity (mU/mg of wet tissue) Results are expressed as mean \pm s.e.m. ${ }^{\star} P<0.05$ was considered significant. This figure shows data for seven to 10 mice per group.

In addition to measure circulating levels of cytokines, we also determined the local pancreatic level of IL-6 before and after 12 hourly intraperito- neal injections of cerulein. As shown in Figure 8, cerulein-induced pancreatitis in WT and PARP-2 ${ }^{-1-}$ mice is associated with an increase in the local pancreatic IL-6 level that was significantly attenuated by the pharmacological or genetic blockade of PARP-1.

\section{Effect of Genetic and Pharmacological Blockade of PARPs on Pancreatitis-Associated Lung Injury}

Severity of acute pancreatitis is associated with lung injury. Accordingly, we assessed the extent of lung injury in $\mathrm{WT}$, PARP-1 ${ }^{-/-}, \mathrm{PARP}^{-2^{-/-}} \mathrm{WT}^{\mathrm{PJ} 34}$ and $\mathrm{WT}^{3-\mathrm{AB}}$ mice after 12 hourly intraperitoneal injections of cerulein. Morphological analysis of H\&Estained lung sections showed that thick alveolarcapillary membranes grew thicker due to hyperemia, polymorphonuclear and some mononuclear cells infiltration and pneumocytic type-II proliferation in WT and PARP-2 $2^{-1-}$ cerulein-treated mice. Alveolar exudation and/or transudation within the alveoli were minimal. By contrast, these morphological features appeared almost diminished in ceruleintreated PARP-1 ${ }^{-/}$mice. Likewise, PARP inhibitors markedly attenuated cerulein insult to lungs of WT mice under the same experimental conditions (Figure 9). Reduced lung inflammation after PARP 

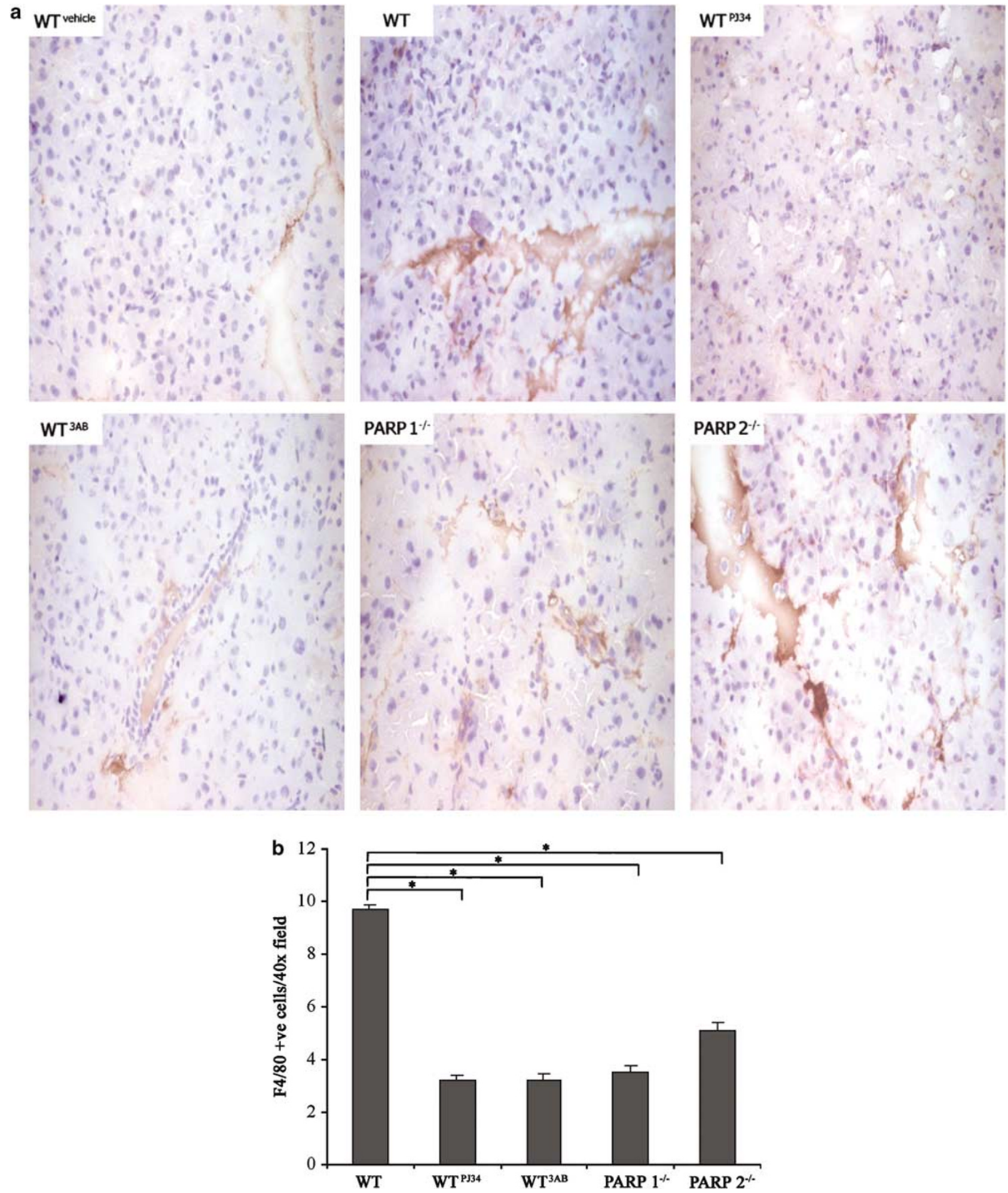

Figure 6 (a) Macrophages infiltration in pancreas induced by cerulein treatment. Representative light micrographs of pancreas sections stained for F4/80 from WT, WT PJ34-treated (WT $\left.{ }^{\mathrm{PJ} 34}\right)$, WT 3-AB-treated (WT ${ }^{3-\mathrm{AB}}$ ), PARP-1 ${ }^{-1-}$ and PARP- $2^{-1-}$ mice administered 12 hourly intraperitoneal injections of $50 \mu \mathrm{g} / \mathrm{kg}$ cerulein. A control (untreated) WT mouse is show. Magnifications $\times 40$. (b) Average number of F4/ $80^{+}$cells/field. Results are expressed as mean \pm s.e.m. ${ }^{*} P<0.05$ was considered significant. This figure shows data for five mice per group.

inhibition has also been reported in other experimental models of acute inflammatory response. ${ }^{16,32}$ Saline-injected mice from all experimental groups showed no morphological evidence of lung injury (Figure 9). As an additional quantitative assessment of the inflammatory response, lung MPO activity 

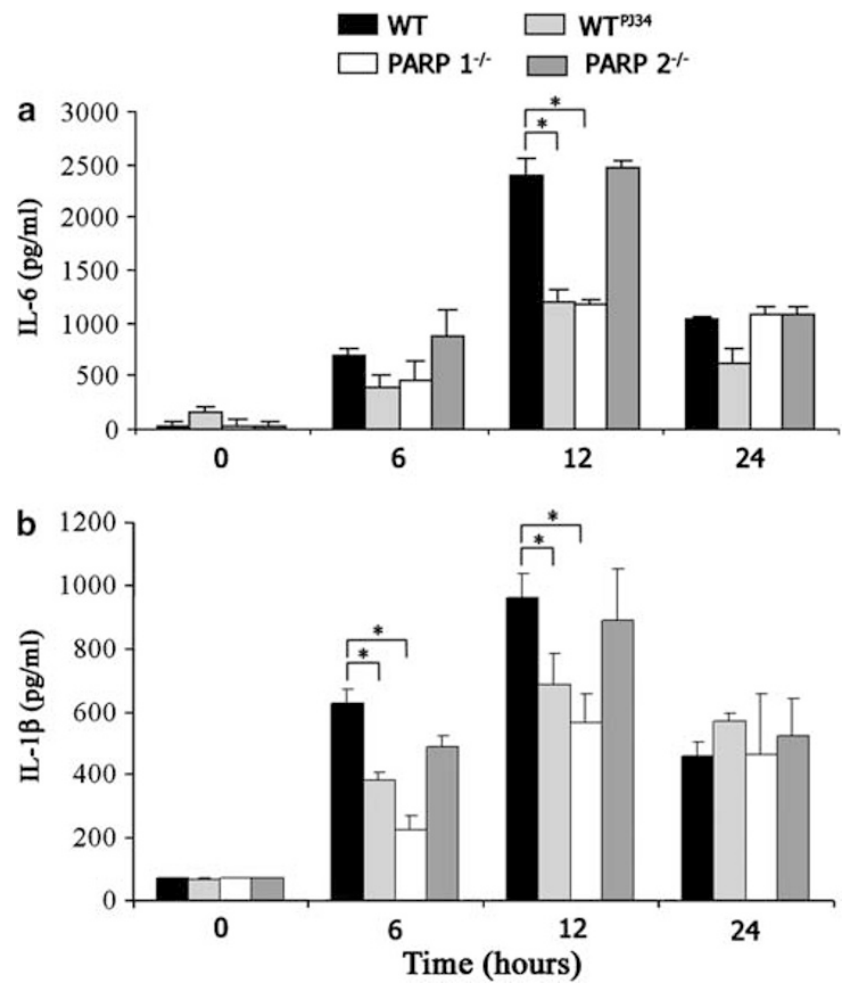

Figure 7 Circulating levels of IL-6 and IL-1 $\beta$ in ceruleinchallenged mice. Serum levels of IL-6 (a) and IL-1 $\beta$ (b) in WT, WT PJ34-treated ( $\mathrm{WT}^{\mathrm{PJ} 34}$ ), PARP-1 ${ }^{-/-}$and PARP-2 ${ }^{-1-}$ mice were quantified by ELISA at different times after cerulein injection. Results are expressed as mean \pm s.e.m. ${ }^{*} P<0.05$ was considered significant. This figure shows data for seven to 10 mice per group.

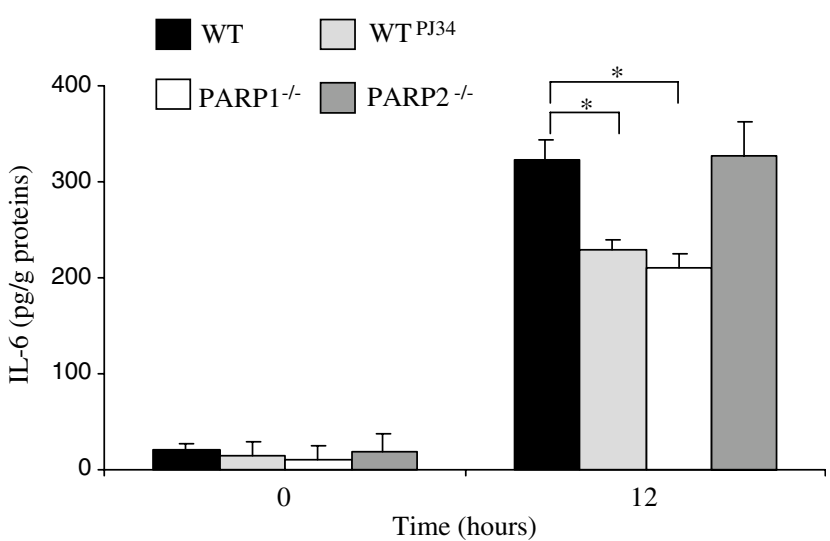

Figure 8 Effects of genetic and pharmacological inhibition of PARPs on pancreatic IL-6 levels. IL-6 levels were measured by ELISA in pancreatic proteins from WT, WT PJ34-treated (WT $\left.{ }^{\mathrm{PJ} 34}\right)$, PARP-1 ${ }^{-1-}$ and PARP- $2^{-1-}$ mice after 12 hourly injections of $50 \mu \mathrm{g} / \mathrm{kg}$ cerulein. Results are expressed as mean + s.e.m. ${ }^{*} P<0.05$ was considered significant. This figure shows data from six mice per group.

following cerulein-induced pancreatitis was measured. MPO activity after 12 hourly intraperitoneal injections of cerulein was significantly higher in WT and PARP $-2^{-/}$mice than that found in PARP-1 ${ }^{-/}$, $\mathrm{WT}^{\mathrm{PJ} 34}$ or $\mathrm{WT}^{3-\mathrm{AB}}$ mice (Figure 10).

\section{Discussion}

The earliest events in the evolution of acute pancreatitis lead to intra-acinar cell activation of digestive enzymes within the pancreas. ${ }^{33}$ Additionally, the severity of the disease results from nonacinar cell mechanisms, including the transmigration and activation of leukocytes within the pancreas and the local synthesis and release of proinflammatory-soluble mediators that transform a local injury into a systemic inflammatory response. $^{3-7}$ Based on recent reports stating that PARP-1 plays a relevant role in cell necrosis and organ failure in various diseases associated with inflammation, ${ }^{15-19}$ we set out to investigate whether genetic and pharmacological blockade of PARP-1 or PARP-2 (a novel member of the PARP family) might affect the development and severity of pancreatitis in the well-characterized cerulein-induced murine model of acute pancreatitis. This model is characterized by hypermylasemia and hyperlipasemia, extensive acinar cell vacuolization, pancreatic edema, intrapancreatic activation of digestive zymogens including trypsinogen, neutrophils sequestration within the pancreas and varying degrees of acinar cell necrosis. ${ }^{31}$

We found that deletion of PARP-2 significantly reduced the serum level of amylase compared to those found in WT mice after cerulein-induced pancreatitis. However, our results show that genetic deletion of PARP-2 has only minor effects in the inflammatory response associated to acute pancreatitis. The role of PARP-2 in the inflammatory response is unknown, and to our knowledge, only one report has been previously shown that inhibition of PARP-2, by using antisense oligonucleotide, attenuated inflammation in colitis. ${ }^{34}$ Thus, our data confirm previous data suggesting an apparent divergence between enzyme secretion and inflammation associated with pancreatitis. ${ }^{35,36}$ In contrast, genetic deletion of PARP-1 attenuated the majority of severity parameters associated with ceruleininduced pancreatitis that have been analyzed. PARP activity is mediated mainly by PARP-1, the best known member of the recently established PARP family, ${ }^{22}$ while PARP-2 is responsible for only 10$15 \%$ of the total PARP activity in cellular extracts fully stimulated by DNA strand breaks. ${ }^{23}$ The difference in activity reported for each PARP enzyme could partly account for the different protection exerted by the genetic deletion of each of these enzymes. Interestingly, pharmacological inhibition of PARP activity by PJ34 or $3-\mathrm{AB}$ has

Figure 9 Morphological changes of pancreatitis-associated lung injury. Representative light micrographs of lung sections stained with H\&E from WT, WT PJ34-treated (WT ${ }^{\mathrm{PJ} 34}$ ), WT 3-AB-treated (WT ${ }^{3-\mathrm{AB}}$ ), PARP-1 ${ }^{-1-}$ and PARP-2 ${ }^{-1-}$ mice administered 12 hourly intraperitoneal injections of $50 \mu \mathrm{g} / \mathrm{kg}$ cerulein (right column) or saline (left column). Magnifications $\times 20$. 
Vehicle

\section{Cerulein}

1259

WT
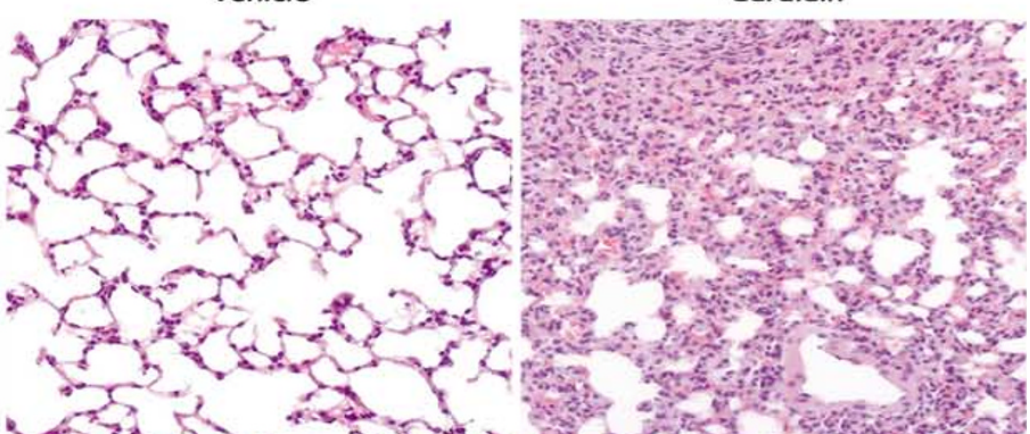

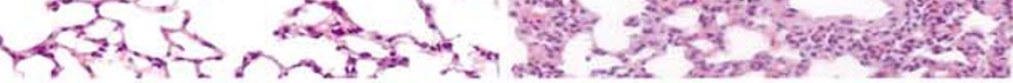

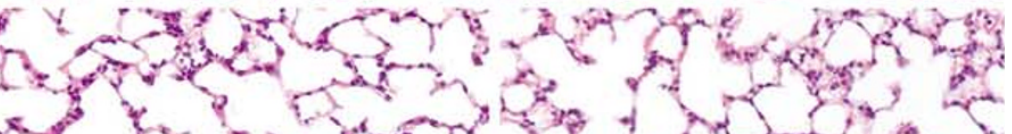

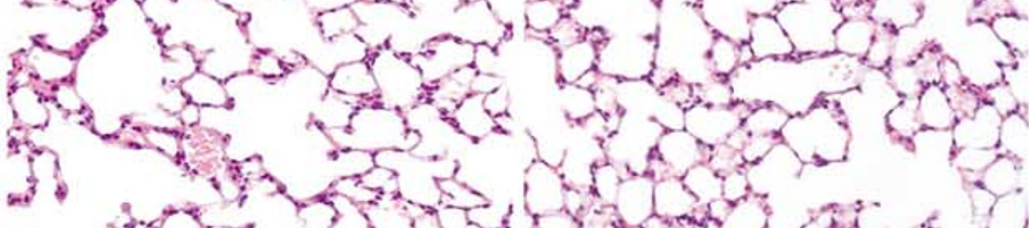

WT $^{\text {PJ34 }}$

ats

PARP $1 \%$
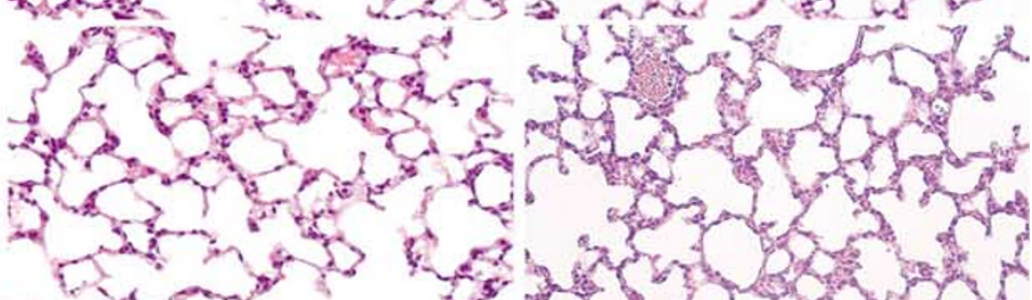

WT ${ }^{3 A B}$

PARP $2 \%$
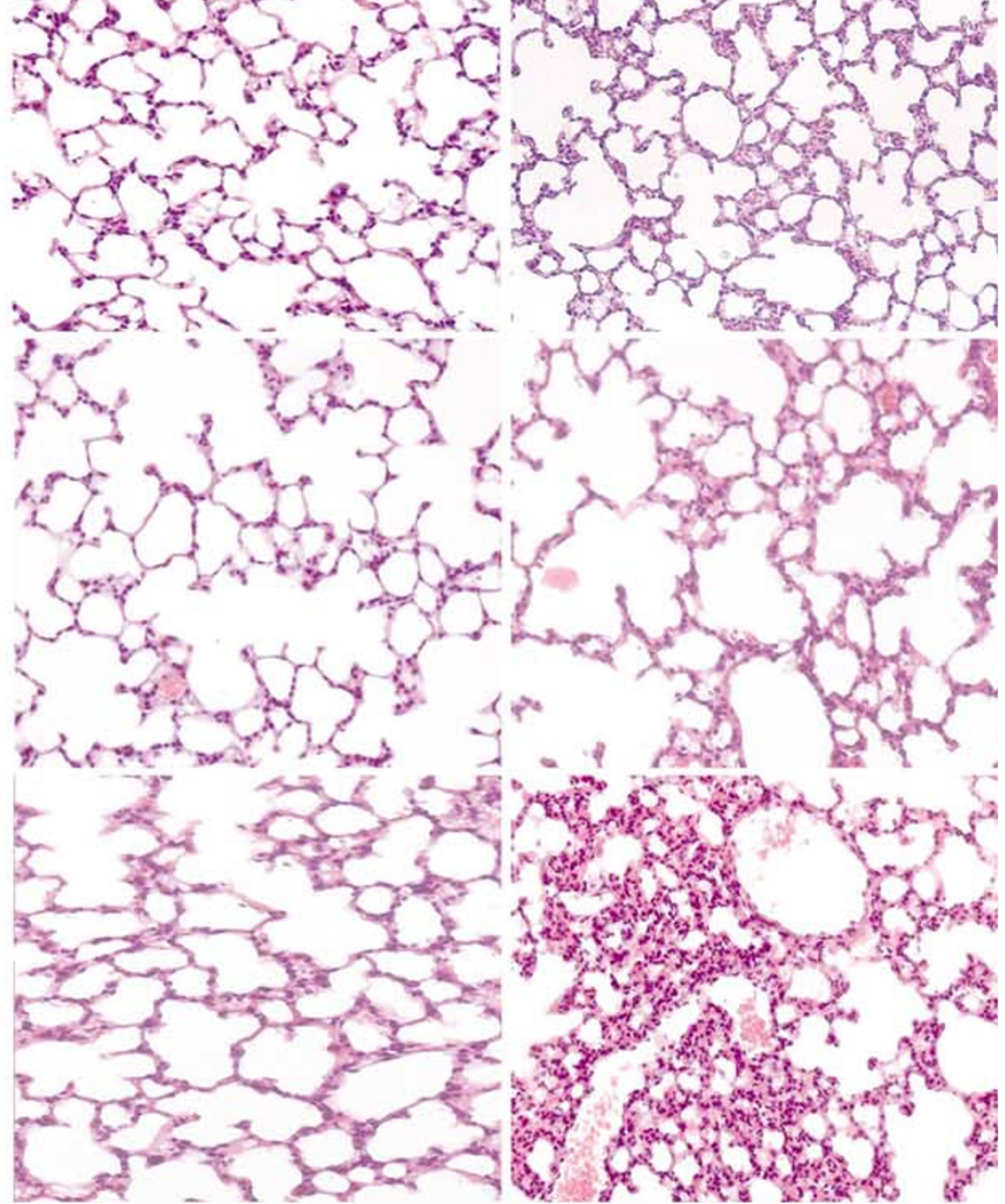


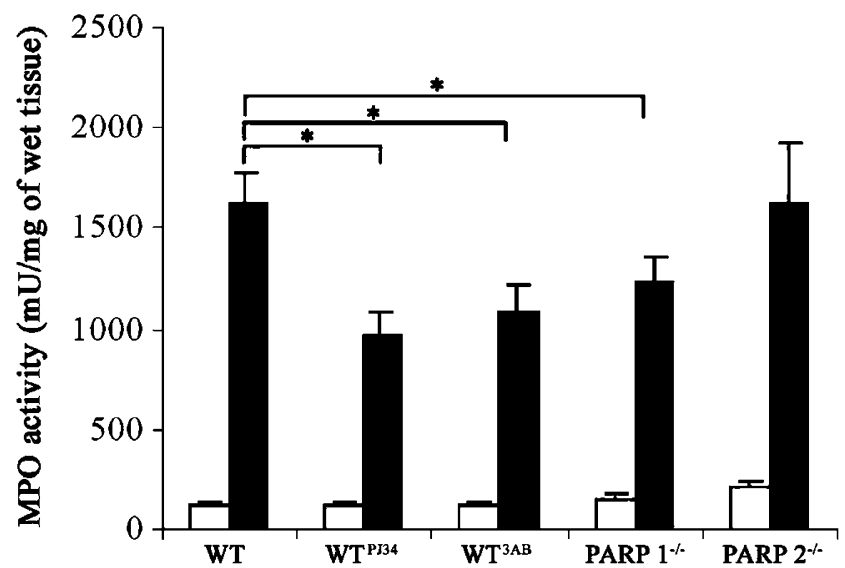

Figure 10 Effects of genetic and pharmacological inhibition of PARP on lung MPO activity. MPO activity was measured in lungs of WT, WT PJ34-treated (WT ${ }^{\mathrm{PJ} 34}$ ), WT 3-AB-treated (WT ${ }^{3-\mathrm{AB}}$ ), PARP-1 ${ }^{-1-}$ and PARP-2 ${ }^{-1-}$ mice after 12 hourly injections of $50 \mu \mathrm{g} / \mathrm{kg}$ cerulein (black bars). The same numbers of control animals from each experimental group received saline (white bars). Data are expressed as MPO activity (mU/mg of wet tissue). Results are expressed as mean \pm s.e.m. ${ }^{*} P<0.05$ was considered significant. This figure shows data for seven to 10 mice per group.

the strongest effect on controlling the severity of the process. PARP inhibitors such as PJ34 or $3-\mathrm{AB}$ compete with the substrate $\mathrm{NAD}^{+}$for the catalytic domain of PARP enzymes. ${ }^{37}$ This domain is highly conserved between PARP-1 and -2 enzymes. ${ }^{21}$ Thus, both PJ34 and 3-AB inhibit PARP-1 and -2 catalytic activities, thereby exerting a cumulative protective effect as a result of blocking the overlapping function of both PARP-1 and PARP2 enzymes. ${ }^{38}$ However, we cannot rule out that PJ34 or 3-AB might also inhibit the activity of other PARP family members that could play a role in pancreatitis.

The model proposed by this paper suggests that PARP inhibition might control the severity of acute pancreatitis by preventing both the local and systemic inflammatory response, and the mechanisms involved in pancreatic cell necrosis mediated by neutrophils via the enzyme nicotinamide adenine dinucleotide phosphate (NADPH) oxidase ${ }^{5}$ (Figure 11). Endothelial cell and acinar expression of adhesion molecules and chemokines during the initial steps of pancreatitis promotes neutrophil adhesion to the endothelial cell surfaces, neutrophil diapedesis and sequestration of neutrophils within the pancreatic parenchyma. ${ }^{4}$ We have recently shown that PARP inhibition reduces the expression of inflammatory mediators involved in endothelial cell transmigration, and therefore reduce the adhesion of leukocytes to endothelial cells, results that have been confirmed by some other groups. ${ }^{17,39,40}$ Accordingly, herein we have found a significant reduction in cell infiltration and MPO activity in pancreas from cerulein-induced pancreatitis mice after PARP inhibition (see Figures 2, 5 and 6). In a second step, once inside the tissue, neutrophil
NADPH oxidase initiates the generation of reactive oxygen species (ROS) including hydrogen peroxide and superoxide. ${ }^{5}$ Rapid DNA single-stranded breaks are induced by ROS, leading to overactivation of PARP and depletion of cellular energy resulting in mitochondrial free radical generation and cell necrosis. ${ }^{41,42}$ In our model, PARP inhibition will also block this process and therefore attenuate cell necrosis (Figure 11). In a third step, severe episodes of acute pancreatitis are associated with a systemic inflammatory response. Indeed, serum levels of different cytokines such as IL-6 and IL-1 $\beta$ are increased during acute pancreatitis, ${ }^{7}$ although the correlation between IL-6 serum levels with the severity of the disease is controversial. ${ }^{43-45} \mathrm{We}$ found increased levels of IL- 6 and IL- $1 \beta$ in serum from cerulein-treated WT and PARP-2 ${ }^{-1-}$ mice, suggesting that PARP-2 did not play any role on the expression of this inflammatory mediators. However, the serum levels of IL-6 and IL- $1 \beta$ were reduced in PARP-1 $1^{-/-}$and $\mathrm{WT}^{\mathrm{PJ} 34}$ mice after cerulein-induced pancreatitis compared with WT mice. Similarly, pancreatitis-associated lung injury, mediated by the release of systemic inflammatory mediators, was attenuated in PARP-1 $1^{-1-}$ and $\mathrm{WT}^{\mathrm{P} 334}$ mice but not in PARP-2 mice. A large body of studies has shown a role for PARP-1 and pharmacological PARP inhibitors in the systemic inflammatory response, by regulating the activity of NF- $\kappa \mathrm{B}$ and other transcription factors. ${ }^{15-19}$ Therefore, PARP inhibition could also block this critical step in the severity of acute pancreatitis as reported in other pathophysiological processes associated with systemic inflammation (Figure 11).

In summary, we show that genetic deletion of PARP-1, but not PARP-2, attenuates the severity of acute pancreatitis and pancreatitis-associated lung injury. Therefore, PARP- 1 appears as a new potential therapeutic target molecule in acute pancreatitis. Interestingly, pharmacological inhibition of PARP activity has the strongest effect on controlling the severity of acute pancreatitis and pancreatitisassociated lung injury. PARP inhibition might control acute pancreatitis by preventing both the local and systemic inflammatory response and the mechanisms of pancreatic cell necrosis mediated by ROS released via the neutrophil enzyme NADPH oxidase. These findings support the potential therapeutic use of PARP inhibitors in the development and severity of acute pancreatitis and associated lung injury.

\section{Acknowledgements}

We appreciate the collaboration of Dr Gilbert de Murcia (Strasbourg, France) who kindly provided PARP $-1^{-/-}$and PARP-2 ${ }^{-1-}$ mice, and Dr Javier Corral for critical reading of the manuscript. This work was supported by the Instituto de Salud Carlos III (Grants PI021138, PI030704 and C03/02) and Fun- 


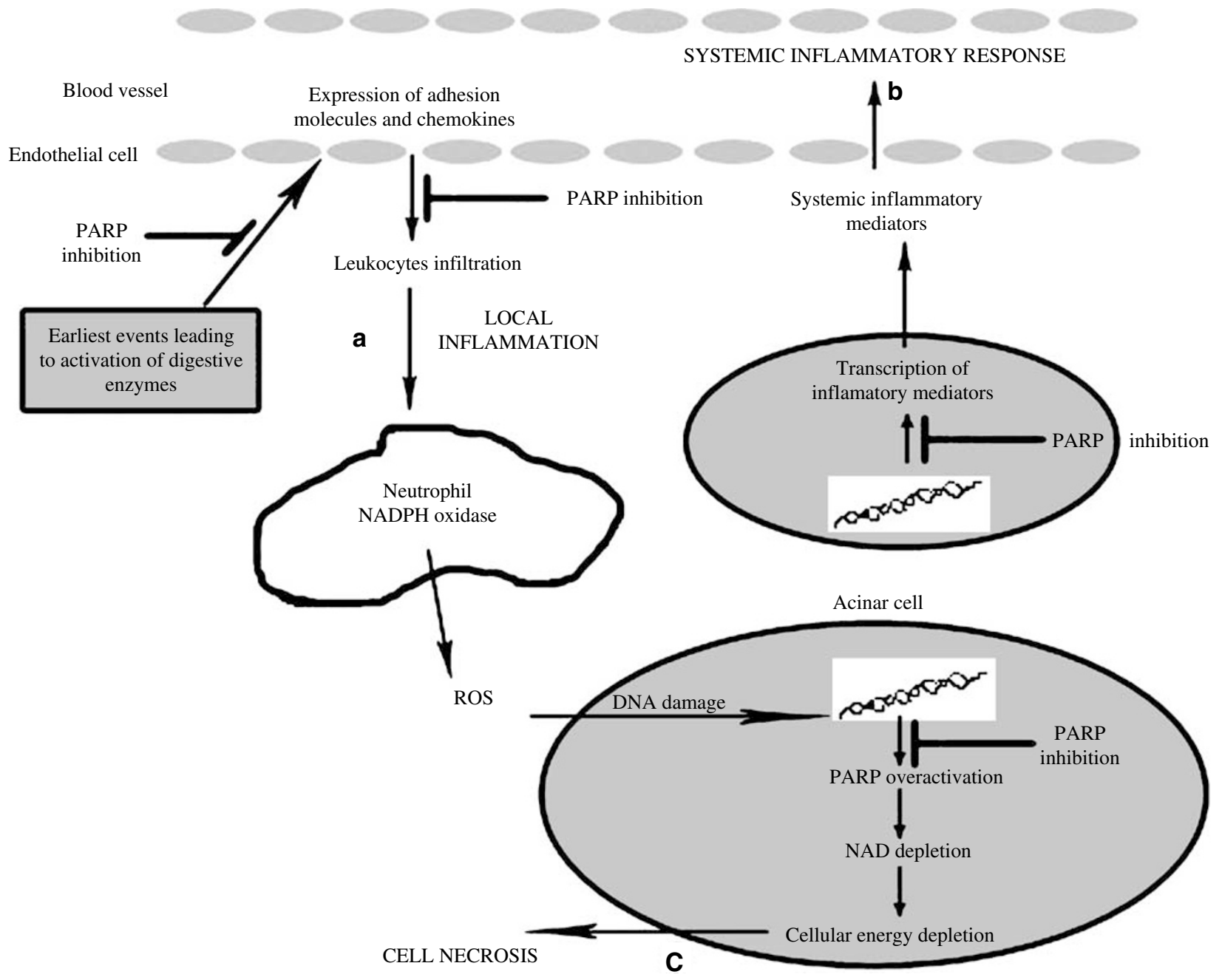

Figure 11 PARP inhibition might protect against acute pancreatitis at different levels. (a) Regulation of local and (b) systemic inflammation by inhibiting expression of inflammatory mediators. (c) PARP acts as a sensor of DNA damage in cells with increased ROS with the following consequences on energy depletion and necrosis. ROS, reactive oxygen species.

dación Séneca (Grants PB/64/FS/02 and 00603/PI/ 04). JY is an Investigator from the Ramón y Cajal Program.

\section{References}

1 Imrie CW. Acute pancreatitis: overview. Eur J Gastroenterol Hepatol 1997;9:103-105.

2 Steer M. Pancreatitis severity: who calls the shots? Gastroenterology 2002;122:1168-1172.

3 Norman J. The role of cytokines in the pathogenesis of acute pancreatitis. Am J Surg 1998;175:76-83.

4 Zaninovic V, Gukovskaya AS, Gukovsky I, et al. Cerulein upregulated ICAM-1 in pancreatic acinar cells, which mediates neutrophils adhesion to these cells. Am J Physiol 2000;279:G666-G676.

5 Gukovskaya AS, Vaquero E, Zaninovic V, et al. Neutrophils and NADPH oxidase mediate intrapancreatic trypsin activation in murine experimental acute pancreatitis. Gastroenterology 2002;122:974-984.
6 Frossard JL, Saluja A, Bhagat L, et al. The role of intercellular adhesion molecule 1 and neutrophils in acute pancreatitis and pancreatitis-associated lung injury. Gastroenterology 1999;116:694-701.

7 Bathia M, Brady M, Shokuhi S, et al. Inflammatory mediators in acute pancreatitis. J Pathol 2000;190: 117-125.

8 Pahl HL. Activators and target genes of Rel/NF- $\kappa \mathrm{B}$ transcription factors. Oncogene 1999;18:6853-6866.

9 Hughes CB, Grewal HP, Gaber LW, et al. Anti-TNF- $\alpha$ therapy improves survival and ameliorates the pathophysiologic sequelae in acute pancreatitis in the rat. Am J Surg 1996;171:274-280.

10 Denharn W, Norman J. The potential role of therapeutic cytokine manipulation in acute pancreatitis. Surg Clin N Am 1999;79:767-781.

11 Gukovsky I, Gukovskaya AS, Blinman TA, et al. Early NF-kappaB activation is associated with hormoneinduced pancreatitis. Am J Physiol 1998;275:G1402G1414.

12 Satoh A, Shimosegawa T, Fujita M, et al. Inhibition of nuclear factor-kappaB activation improves the survival 
of rats with taurocholate pancreatitis. Gut 1999;44: 253-258.

13 Ethridge RT, Hashimoto K, Chung DH, et al. Selective inhibition of NF-kappaB attenuates the severity of cerulein-induced acute pancreatitis. Am J Coll Surg 2002;195:497-505.

14 Altavilla D, Famulari C, Passaniti M, et al. Attenuated cerulein-induced pancreatitis in nuclear factor- $\kappa \mathrm{B}$ deficient mice. Lab Invest 2003;12:1723-1732.

15 Oliver FJ, Menissier-de Murcia J, Nacci C, et al. Resistance to endotoxic shock as a consequence of defective NF-kappaB activation in poly (ADP-ribose) polymerase-1 deficient mice. EMBO J 1999;18: 4446-4454.

16 Corral J, Yélamos J, Hernández-Espinosa D, et al. Role of lipopolysaccharide and cecal ligation and puncture on blood coagulation and inflammation in sensitive and resistant mice models. Am J Pathol 2005;166: 1089-1098.

17 Carrillo A, Monreal Y, Ramirez P, et al. Transcription regulation of TNF- $\alpha$-early response genes by poly(ADPribose) polymerase- 1 in murine heart endothelial cells. Nucleid Acids Res 2004;32:757-766.

18 Soriano FG, Liaudet L, Szabo E, et al. Resistance to acute septic peritonitis in poly(ADP-ribose) polymerase-1-deficient mice. Shock 2002;17:286-292.

19 Veres B, Gallyas Jr F, Varbiro G, et al. Decrease of the inflammatory response and induction of the Akt/ protein kinase B pathway by poly-(ADP-ribose) polymerase 1 inhibitor in endotoxin-induced septic shock. Biochem Pharmacol 2003;65:1373-1382.

20 de Murcia G, Shall S. From DNA Damage and Stress Signalling to Cell Death: Poly(ADP-Ribosylation) Reactions. Oxford University Press: Oxford, 2000.

21 Amé JC, Rolli V, Schreiber V, et al. PARP-2, A novel mammalian DNA damage-dependent poly(ADP-ribose) polymerase. J Biol Chem 1999;274:17860-17868.

22 Amé JC, Spenlehauer C, de Murcia G. The PARP superfamily. Bioessays 2004;26:1-12.

23 Schreiber V, Amé JC, Dollé P, et al. Poly(ADP-ribose) polymerase-2 (PARP-2) is required for efficient base excision DNA repair in association with PARP-1 and XRCC1. J Biol Chem 2002;277:23028-23036.

24 Menissier de Murcia J, Ricoul M, Tartier L, et al. Functional interaction between PARP-1 and PARP-2 in chromosome stability and embryonic development in mouse. EMBO J 2003;22:2255-2263.

25 Garcia Soriano F, Virág L, Jagtap P, et al. Diabetic endothelial dysfunction: the role of poly(ADP-ribose) polymerase activation. Nat Med 2001;7:108-113.

26 Jagtap P, Garcia Soriano F, Virág L, et al. Novel phenanthridinone inhibitors of poly(adenosine 5 -diphosphate-ribose) synthetase: potent cytoprotective and antishock agents. Crit Care Med 2002;30: 1071-1082.

27 Purnell MR, Whish WJ. Novel inhibitors of poly(ADPribose) synthetase. Biochem J 1980;185:775-777.

28 Menissier-de Murcia J, Niedergang C, Trucco C, et al. Requirement of poly(ADP-ribose) polymerase in recovery from DNA damage in mice and in cells. Proc Natl Acad Sci USA 1997;94:7303-7307.

29 Cuzzocrea S, Zingarelli B, Gilad E, et al. Protective effects of 3-aminobenzamide, an inhibitor of poly(ADPribose) synthase in a carrageenan-induced model of local inflammation. Eur J Pharmacol 1998;342: 67-76.
30 Van Laethem JL, Marchant A, Delvaux A, et al. Interleukin 10 prevents necrosis in murine experimental acute pancreatitis. Gastroenterology 1995;108: 1917-1922.

31 Steer ML. Models for the study of pancreatitis. In: Souba W, Wilmore D (eds). Surgical Research. Academic Press: San Diego, CA, 2001, pp 733-746.

32 Liaudet L, Pacher P, Mabley JG, et al. Activation of poly(ADP-ribose) polymerase-1 is a central mechanism of lipopolysaccharide-induced acute lung inflammation. Am J Respir Crit Care Med 2002;165:372-377.

33 Grady T, Saluja A, Kaiser A, et al. Edema and intrapancreatic trypsinogen activation precede glutathione depletion during caerulein pancreatitis. Am J Physiol 1996;271:G20-G26.

34 Popoff I, Jijon H, Monia B, et al. Antisense oligonucleotides to poly(ADP-ribose) polymerase-2 ameliorate colitis in interleukin-10-deficient mice. J Pharmacol Exp Ther 2002;303:1145-1154.

35 Ethridge RT, Chung DH, Slogoff M, et al. Cyclooxygenase-2 gene disruption attenuates the severity of acute pancreatitis and pancreatitis-associated lung injury. Gastroenterology 2002;123:1311-1322.

36 Wagner AC, Mazzucchelli L, Miller M, et al. CEP-1347 inhibits caerulein-induced rat pancreatic JNK activation and ameliorates caerulein pancreatitis. Am J Physiol 2000;278:G165-G172.

37 Banasik M, Komura H, Shimoyama M, et al. Specific inhibitors of poly(ADP-ribose) synthetase and mono (ADP-ribosyl)transferase. J Biol Chem 1992;267: 1569-1575.

38 Iwashita A, Tojo N, Matsuura S, et al. A novel and potent poly(ADP-ribose) polymerase-1 inhibitor, FR247304 (5-chloro-2-[3-(4-phenyl-3,6-dihydro-1(2H)pyridinyl)propyl]-4(3H)-quinazolinone), attenuates neuronal damage in in vitro and in vivo models of cerebral ischemia. J Pharmacol Exp Ther 2004;310: 425-436.

39 Sharp C, Warren A, Oshima T, et al. Poly ADP ribosepolymerase inhibitors prevent the upregulation of ICAM-1 and E-selectin in response to Th1 cytokine stimulation. Inflammation 2001;25:157-163.

40 Haskó G, Mabley JG, Németh ZH, et al. Poly(ADPribose) polymerase is a regulator of chemokine production: relevance for the pathogenesis of shock and inflammation. Mol Med 2002;8:283-289.

41 Szabó C, Dawson VL. Role of poly(ADP-ribose) synthetase in inflammation and ischaemia-reperfusion. Trends Pharmacol Sci 1998;19:287-297.

42 Hwang JJ, Choi SY, Koh JY. The role of NADPH oxidase, neuronal nitric oxide synthase and poly(ADP ribose) polymerase in oxidative neuronal death induced in cortical cultures by brain-derived neurotrophic factor and neurotrophin-4/5. J Nerochem 2002;82: 894-902.

43 de Beaux AC, Goldie AS, Ross JA, et al. Serum concentrations of inflammatory mediators related to organ failure in patients with acute pancreatitis. Br J Surg 1996;83:349-353.

44 Inagaki T, Hoshino M, Hayakawa T, et al. Interleukin-6 is a useful marker for early prediction of the severity of acute pancreatitis. Pancreas 1997;14:1-8.

45 Cuzzocrea S, Mazzon E, Dugo L, et al. Absence of endogenous interleukin-6 enhances the inflammatory response during acute pancreatitis induced by cerulein in mice. Cytokine 2002;18:274-285. 